ISSN: 2792-3967

D01: https://doi.org/l0.5370I/shj.vlil.7

\title{
BASES PARA UNA POÉTICA DE LA ESPERANZA: CONTENIDO PROPOSICIONAL Y AUTONOMÍA DE LA IMAGEN ${ }^{1}$
}

FOUNDATION FOR A POETICS OF HOPE: PROPOSITIONAL

CONTENT AND IMAGE AUTONOMY

\author{
Adrián Pradier \\ Universidad de Valladolid, España \\ ORCID: 0000-000I-5546-4238 \\ adrian.pradier@uva.es
}

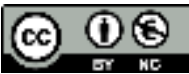

\begin{abstract}
| Resumen | El objetivo del artículo consiste en presentar las bases para una poética de la esperanza, conforme a una estrategia de tres fases: en primer lugar, se estudia la discusión contemporánea del concepto de esperanza en el marco de la filosofía analitica $y$, en particular, se discuten las principales fortalezas y debilidades de la "descripción estándar» (standard account), conceptualización que goza de rango canónico; tras presentar las principales deficiencias del modelo, se discute el estatu to de las imágenes mentales como criterio definitorio a propósito de un trabajo de Luc Bovens, con el objetivo de poner de manifiesto la naturaleza proposicional del contenido mental de la esperanza; resuelta ya la separación entre imágenes mentales adscritas a la esperanza y los contenidos discursivos consustanciales a ella, se justifica la licencia de una poética de la esperanza en sus lineamentos básicos.
\end{abstract}

Palabras clave: Esperanza, Descripción estándar, Imagen, Autonomía, Poética.

\footnotetext{
Abstract | The aim of the article is to present the bases for a poetics of hope, according to a three-phase strategy: first, we study the contemporary discussion of the concept of hope within the framework of analytical philosophy and, in particular, we discuss the main strengths and weaknesses of the standard account, the only conceptualization with a certain canonical rank. Once the main deficiencies of the model have been presented, we then analyse the status of mental images as a defining criterion in the definition of hope, in order to reveal the propositional nature of its mental content. For this we take as a basis Luc Bovens' work on the deficiencies of the standard approach. Once the separation between mental images attached to hope and discursive contents inherent to it has been resolved, we propose and justify the license to elaborate a poetics of hope in its basic guidelines.
}

Keywords: Hope, Standard Account, Image, Autonomy, Poetics,

' Recibido/Received: |3/05/202|

Aceptado/Accepted: 07/06/202I 


\section{| Introducción ${ }^{2}$ |}

La búsqueda de una definición satisfactoria de esperanza ha sido durante las dos últimas décadas objeto de una inusitada atención filosófica, especialmente en el marco de la filosofía analítica. Mi objetivo no consiste ni en discutir una definición de esperanza, ni en realizar un balance de las principales contribuciones al respecto. Se trata más bien de proponer las bases para una poética de la esperanza y, sobre todo, de justificar el origen de su elaboración.

La estructura del trabajo, que tiene algo de estrategia, recorre tres fases: atendiendo a su influencia y rango canónico, se analiza, en primer lugar, la «descripción estándar» de la esperanza en el contexto analítico contemporáneo; seguidamente se discuten las consecuencias de un trabajo publicado por Luc Bovens sobre las insuficiencias del modelo estándar, entre las que destaca, para nuestros propósitos, el estatuto autónomo de las «imágenes mentales» de la esperanza en relación al «contenido proposicional» de la misma; despejada la neta separación entre ambos, se procede a justificar y habilitar, por último, la licencia de una poética de la esperanza basada en tres principios básicos, atinentes a su norma, objetivo y horizonte.

\section{| El enfoque analítico de la esperanza: la «descripción estándar»|}

La caracterización más aceptada de la esperanza es la «descripción estándar» (Meirav, 2009, p. 218) u «ortodoxa» (Martin, 2014, p. 4). En ella se define como una «disposición» mental (Day, 1969, p. 98) en la que han de satisfacerse dos condiciones: (1) una condición desiderativa, por la que la proposición «A tiene esperanza de que p» es cierta si y sólo si «A desea el cumplimiento, ocurrencia o posesión de p»; (2) una condición cognitiva o estimativa, en la que para que la proposición «A tiene esperanza de que p» sea verdadera es preciso que «A crea subjetivamente que $p$ es en algún grado probable». Se acepta, en general, que esta creencia o estimación ha de involucrar «un cierto rango de probabilidades» (Downie, 1963, p. 248) que habilite, al mismo tiempo, un «grado de expectación» adecuado, de tal forma que, al contrario, una persona desesperanzada, sin estar falta de deseo, carece no obstante «de una expectación de que este deseo se cumpla» (Wheatley, 1958, p. 127).

El filósofo analítico Robert S. Downie, tomando en consideración un trabajo anterior de J.M.O. Wheatley, fue el primero en estudiar el estatuto epistémico de la condición estimativa en la esperanza. A diferencia del planteamiento clásico de Santo Tomás, donde el carácter lógicamente posible de lo esperado constituye por sí solo razón suficiente para legitimar las esperanzas de que $p$, para Downie los casos típicos en los que alguien esperaría que $p$ «caen dentro de una escala más estrecha», coincidente con

\footnotetext{
* Esta publicación se vincula al Proyecto de Investigación "Arte y Transformación Social (A\&TS)" (PIUNA-2020) financiado por la Universidad de Navarra y desarrollado en el GIR "Estética y Arte Contemporáneo", coordinado por el Dr. Ricardo I. Piñero Moral, Catedrático de Estética y Teoría de las Artes.
} 
una «probabilidad positiva de que el objeto de la esperanza se cumpla», distinción que se realiza «con fines prácticos» (Downie, 1963, p. 249). Según este planteamiento, aquellas proposiciones que satisfagan el contenido elemental de «tener esperanzas de que p» tendrán sentido si y sólo si existe el deseo de que $p$ y, al mismo tiempo, existe la creencia en la probabilidad positiva de que $p$ sea mayor que cero y menor que uno, lo cual incluye aquellos casos en los que el éxito es difícil de obtener por razón de probabilidad (Downie, 1963, p. 250; Day, 1969, p. 95).

El rango no es fácil de determinar y ha de mantenerse en un sutil equilibrio entre certidumbre e incertidumbre, pues así como ésta conduciría a la quiebra de la esperanza, un conocimiento cierto y determinista también conduciría a su colapso al «sobrepasar el criterio de probabilidad» (1963, p. 248) en beneficio de una seguridad expectante. En otras palabras, cuanta más certidumbre tenemos en torno a las probabilidades de éxito de que $p$, con más razón se pierden los motivos para esperar y más sentido adquiere mantenerse a la expectativa. La diferencia, por lo tanto, entre «esperanza» y «expectativa», aunque difícil de apreciar en el lenguaje cotidiano, es crítica en la aproximación estándar, tal y como explicaba, en 1969, John Patrick Day:

[...], la visión de que «A espera que $p »$ significa «A desea que $p$ y piensa que $p$ es en algún grado probable» no es idéntica a la definición del diccionario, de acuerdo a la cual significa «A desea y se mantiene a la expectativa de que p». Esto es porque «A se mantiene a la expectativa de que p» no es sinónimo de «A piensa que $p$ es probable en algún grado, aunque sea pequeño», sino que lo es más bien de «A piensa que $p$ es más probable que no». En otras palabras, «A espera que p» es sinónimo de «A cree que p». De manera incidental hay un uso diferente $y$ secundario de «tener expectativas». «Inglaterra tiene la expectativa de que todo hombre este día cumplirá con su deber» ${ }^{3}$ no significa que «los ingleses creen que cada marinero de la flota cumplirá hoy con su deber», sino que significa más bien que «los ingleses confían, o cuentan, con que cada marinero de la Flota cumpla hoy con su deber» (Day, 1969, p. 95).

Las últimas dos décadas han sido especialmente fructíferas tanto en ritmo como en calidad de los trabajos publicados. Y, en la práctica totalidad de los casos, se acusa la inadecuación de la «descripción estándar» de la esperanza, en particular del enfoque dual de condiciones. La controversia contemporánea se centra en el hecho de que la descripción estándar, en su enfoque canónico de las dos condiciones, no es capaz de ofrecer un marco efectivo de resolución a la hora de distinguir entre esperanza y desesperanza. Dicho de otro modo, el modelo es insuficiente. En este sentido, si para otro prestigioso teórico de la esperanza como fue Gabriel Marcel «las condiciones de posibilidad de la esperanza coinciden rigurosamente con aquellas de la desesperanza» (Marcel, 2003 [1931], p. 87), lo que constituye su carácter particular, esta coincidencia genera un fallo catastrófico para el enfoque analítico.

\footnotetext{
${ }^{3}$ La frase England expects that every man will do his duty es un ejemplo bien conocido en lengua inglesa. Se trata de una señal de navegación enviada por Lord Nelson desde el palo mayor del HMS Victory a los barcos de la flota inglesa que participaron en la Batalla de Trafalgar, acaecida el 21 de octubre de 1805 .
}

SHJ, I (I) (202I) pp. I27-I46. ISSN: 2792-3967 
Según se orienten en uno u otro sentido, las principales críticas se agrupan en torno a dos líneas de trabajo bien reconocidas: la menos numerosa, de un lado, está integrada por quienes ponen en cuestión o bien una (Beyleveld, 2012), o bien ambas condiciones de inicio (Segal \& Textor, 2015), o directamente acusan el propio enfoque del modelo de condiciones (Blöser, 2019; Segal \& Textor, 2015; Moellendorf, 2006); la más numerosa en miembros y contribuciones, por el contrario, está integrada por aquellos autores que dirigen todos sus esfuerzos a resolver el problema de la impotencia explicativa del enfoque analítico dual para lograr, entre otras rutinas clave, una distinción adecuada entre aquellas situaciones marcadas por la esperanza de aquellas otras caracterizadas por su contrario, la desesperanza (Kwong, 2019; Milona \& Stockdale, 2018; Martin, 2014; Meirav, 2009; Pettit, 2004; Bovens, 1999).

Bajo el punto de vista del profesor Ariel Meirav (2009), la «descripción estándar» ha sido capaz de ofrecer dos condiciones ciertamente necesarias para la esperanza, pero sin capacidad para explicar las razones por las que, de dos sujetos, en igualdad de condiciones, ante una misma situación y animados por el mismo deseo, uno se mantenga en la esperanza y otro no. Según este planteamiento, la aplicación del modelo dual implica que para que la proposición «tener esperanza de que p» sea verdadera es necesario que se cumpla (1) el deseo de que $p$ y (2) la creencia de que $p$ es en algún grado probable, por lo que una proposición del estilo «no tener esperanza de que p» es verdadera si y sólo si se cumple (1) el deseo de que $p$ y (2) la creencia de que no-p es en algún grado probable. Comoquiera que no se altera ni el número de condiciones, ni el propio contenido proposicional expresado en $p$, esperanza y desesperanza satisfacen, a efectos prácticos, tanto la condición desiderativa como la estimativa, por lo que no sería posible explicar, como tampoco discernir para «un amplio rango de tipos de casos [...] si uno espera o desespera de lo esperado» (Meirav, 2009, p. 230).

Algo parecido sucede en el ejemplo atribuido por Spinoza a Jean Buridan (Spinoza, 1677, II, p. XLIX, sch.), en el que, al no encontrar razones para justificar la elección entre dos pilas de heno en apariencia iguales, un asno muere de hambre. La diferencia radica en que las personas, a diferencia del jumento, se arriesgan o se dejan llevar, y o bien se procuran un rincón en la angosta bodega de la esperanza; o bien naufragan en el mar sereno y calmo de la desesperanza. Pero, en cualquier caso, eligen. Gabriel Segal y Mark Textor ilustran el problema mediante el siguiente ejemplo:

Reinhold y Hillary están escalando una ruta difícil. Todavía están a cierta distancia de la cumbre y están evaluando sus probabilidades. Ambos creen que tienen un cincuenta por ciento de probabilidades de éxito y un cincuenta por ciento de probabilidades de fracaso. Sus deseos de alcanzar la cima son igual de fuertes, como lo son sus deseos de regresar a casa sanos y salvos. En lo que respecta a la psicología de creencias / deseos de Reinhold y Hillary, está en juego la elección entre regresar al campamento base o ascender a la cumbre. ¿Quedarán paralizados, como el asno de Buridan, o sólo serán capaces de resolver el punto muerto lanzando una moneda (Segal \& Textor, 2015, pp. 209-210)? 
En general, la estrategia más compartida entre los autores que aceptan las bases fundacionales de la aproximación estándar consiste en buscar una tercera condición o, en términos de Michael Milona, un «tercer factor»- que permita afrontar esta insuficiencia explicativa (Milona, 2020b, pp. 103-108; Pradier, 2020, pp. 172-183; Blöser, 2019, pp. 206-209; Segal \& Textor, 2015, pp. 241-222; Martin, 2014, 11-34). Analizamos en la siguiente sección la primera de tales propuestas en orden cronológico, firmada por el filósofo belga Luc Bovens, cuyas debilidades argumentativas servirán para poner de manifiesto dos ideas fundamentales para la elaboración de nuestra poética de la esperanza: de un lado, (1) la autonomía de la «imagen mental» en relación al «contenido proposicional» de la esperanza; $y$, de otro lado, (2) la posibilidad de crear y proponer «imágenes» que, con arreglo a la señalada autonomía, incentiven, contribuyan o refuercen los motivos para creer en la resolución favorable de ese mismo «contenido discursivo».

\section{|El modelo representacional de la esperanza de Luc Bovens |}

Las principales propuestas para resolver ese déficit explicativo de la versión estándar de la esperanza arrancaron en 1999 con el trabajo The Value of Hope del filósofo analítico Luc Bovens, para quien también «la conjunción de creencia no segura y deseo es una condición necesaria y no suficiente para la esperanza» (1999, p. 674). Se impone, por lo tanto, la búsqueda de un tercer factor, que para Bovens consiste en una cierta inversión de esfuerzo y energía en actividades mentales que conduzcan a la elaboración de una «imagen mental» plausible y concreta de lo esperado. Quien se embarca en la esperanza, por lo tanto, invierte una cierta cantidad de «energía mental» en aras de imaginar los «estados proyectados del mundo», en cuyas representaciones no sólo puede hallarse un cierto alivio ante las dificultades presentes, o una fuente de fuerza motivacional para adoptar posiciones proactivas, sino que incluso «podemos llegar a darnos cuenta de que, después de todo, no vale la pena esperar lo que originalmente esperábamos» (1999, p. 673).

La «imagen mental» (mental imaging) resultante tiene, por lo tanto, un valor emocional, pues proporciona un descanso de la «espera» presente; un valor cognitivo, por cuanto hasta cierto punto permite anticipar escenarios futuros y hacer cálculos conforme a ellos; y goza de un cierto valor práctico, en tanto que puede animar una revaluación de nuestros objetivos e intereses. Asimismo, permite distinguir al esperanzado del desesperanzado, pues el contenido de ambas imágenes es evidentemente distinto y permite explicar que el primero se comprometa con esa «imagen mental», a cuya luz puede revisar sus opciones, determinar su propio papel como agente $y$, en última instancia, planificar escenarios intermedios. Cabrían supuestos externos, por ejemplo, de tipo caracteriológico o social que, en buena medida, permitirían arrojar algo de luz sobre los motivos que llevarían al esperanzado a comprometerse con ese escenario posible, pero no están expresamente respondidos en el planteamiento original, un aspecto que ya ha recibido sus críticas (Meirav, 2009, p. 226). En todo caos, lo cierto es 
que para Bovens el problema del «tercer factor» habría quedado resuelto. En sus propias palabras:

¿Es la imagen mental, junto con la creencia y el deseo adecuados, una condición suficiente para la esperanza? Creo que sí. Sería ridículo para mí negar que tengo esperanzas de que Sophie venga a la fiesta, al mismo tiempo que creo que podría venir, deseo que venga y soy incapaz de mantener $\mathrm{mi}$ atención en las conversaciones con los demás invitados. ¿Qué más podía haber en la esperanza de que Sophie viniera a la fiesta? Esperar es simplemente tener la creencia y el deseo adecuados junto con estar comprometido hasta cierto punto con la imagen mental (1999, p. 674).

Pese a las bondades de su planteamiento y a su innegable carácter pionero - 0 precisamente por ello-, han sido numerosas las críticas dirigidas contra el trabajo de Bovens, sobre todo por suponer una ruptura de la neta frontera entre el «contenido proposicional» —o «discursivo» (Milona, 2020b, p. 104) — de la esperanza, y las «imágenes mentales» de lo esperado (Meirav, 2009, pp. 226-227; Segal \& Textor, 2015, Pp. 214-216; Martin, 2014, pp. 17-19). De hecho, la decisión de situar entre sus condiciones de satisfacción esta «imagen mental» de lo esperado implica la sustitución, en la teorización sobre la esperanza, de un modelo proposicional dominante, que sí contaría con apoyos hermenéuticos muy claros - amén de argumentativos-, por uno representacional, en el que (1) no sólo la tradición filosófico-moral no ofrece indicios de un arraigo significativo como para tomarlo en consideración, (2) sino que la propia tradición moralista, en sus vías artísticas y literarias, parece defender, en general, los valores de la esperanza frente a los peligros de sus «imágenes mentales» - 0 , al menos, de cierto tipo de imágenes-. Ambos factores permiten presuponer la vigencia del modelo proposicional frente al representacional $y$, lo que es más problemático, la autonomía de la imagen en relación al propio contenido proposicional de lo esperado. Dicho de otro modo, la consideración histórica que las «imágenes mentales» reciben, tanto desde el punto de vista filosófico, como desde el punto de vista literario y artístico, no incluye su necesaria presencia entre las condiciones de la esperanza: antes al contrario, en una proposición del tipo «A espera que p», normalmente se piensa que o bien la imagen de $p$ sobreviene, o es deliberadamente forjada por el sujeto, pero ni en uno ni otro caso es consustancial a la propia esperanza.

Respecto a (1), o sea, la falta de referentes hermenéuticos en la tradición filosófico-moral, cuesta hallar alguna otra referencia filosófica donde se plantee o siquiera se insinúe la idea de la «imagen mental» como una condición necesaria de la esperanza. De hecho, la distinción, en la entraña misma del concepto de esperanza, entre palabra e imagen, así como la condición separable de la segunda es muy antigua. La hallamos ya expresada por primera vez en el Filebo de Platón, en el marco de una auténtica "“psicología" de la esperanza» (Gravlee, 2020, p. 5). En su sentido más amplio, el filósofo ateniense considera que las «esperanzas para el porvenir» (

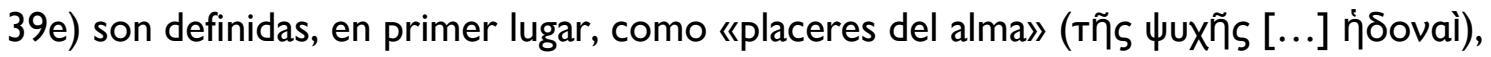
lo que provisionalmente promueve una identificación, de carácter tropológico, entre 
«esperanza» y «placer». Se trata literalmente de un «regocijarse por anticipado»

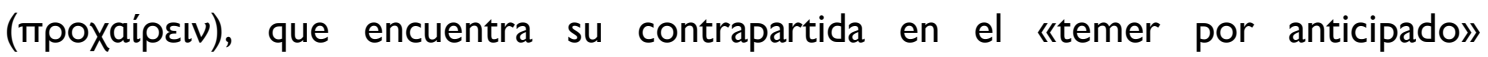

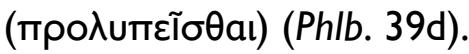

Más adelante se produce una disociación de los conceptos. Cuando Sócrates se pregunta por el modo como se originan nuestros juicios sobre el mundo y compara el alma con

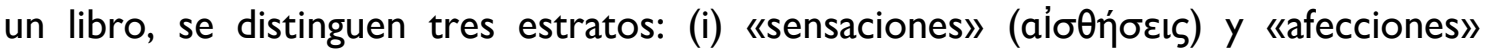

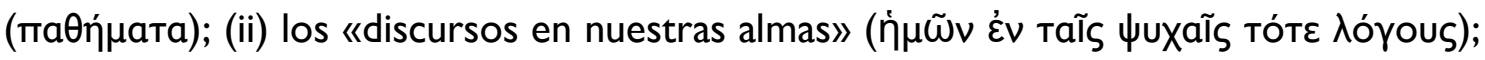

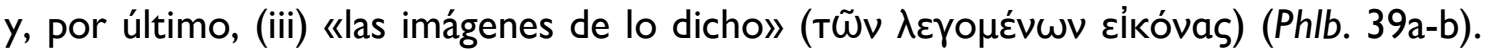
Siguiendo su planteamiento, las esperanzas pasan a ser redefinidas técnicamente como

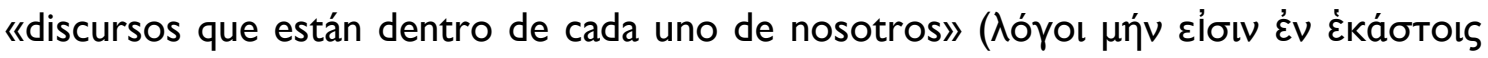

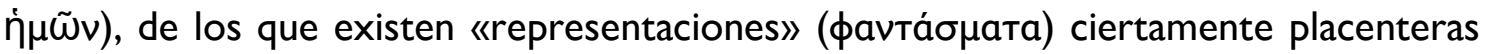
(Phlb. 40a) -lo cual no excluye, en modo alguno, que el contenido proposicional sea, en sí y con anterioridad, placentero-: de esta forma, ya en Platón se consumaba una nítida separación entre «palabra» e «imagen», y, por lo que toca a la esperanza, entre su dimensión discursiva y su representación icónica.

Por lo que respecta a los autores modernos que han trabajado expresamente el concepto de esperanza - y no son muchos-, sólo Spinoza plantea que ésta proviene «de la imagen (ex imagine)», se sobrentiende que mental, «de una cosa futura o pretérita, de cuya ocurrencia dudamos» (ex imagine rei futuræ vel præteritæ de cujus eventu dubitamus), aspecto en el que coincide con el miedo, pues también éste surge «de la imagen de una cosa dudosa» (ex rei dubiæ imagine) (Spinoza, 1677, III, p. XVIII, sch. II).

Descartes, por ejemplo, considera que la esperanza es un tipo de pasión erigida sobre el deseo de un bien —condición desiderativa-, al mismo tiempo que se satisface una estimación —condición estimativa - de su posibilidad, dependiente, a su vez, «de si hay mucho o poco de apariencia de obtener lo que se desea» (s'il y a beaucoup ou peu d'apparence qu'on obtienne ce qu'on désire) (Descartes, 1649, p. 86, art. LVIII). La citada «apariencia», en este punto, no debe confundirse con la «imagen futura» o la «imagen mental», dado que con ello se refiere exactamente al estado de cosas actual y al modo como éste es presentado a los sentidos, con un significado de correlación: en virtud de cómo sea la «apariencia» de las cosas, así será mi esperanza.

Thomas Hobbes, por su parte, considera que la esperanza es un «apetito» (appetite), que necesariamente se conjuga, por su proyección hacia el futuro, «con una opinión de alcanzar lo que se desea» (with an opinion of attaining) (Hobbes, 1995, [1651], Iª, vi, 18, p. 90). Esta opinión parece referirse a las posibilidades de conseguir el objeto esperado, por lo que allí donde hay esperanza, hay una estimación anterior de que suceda lo esperado, con independencia de las imágenes que lo acompañen a las que en momento alguno se refiere. Esto no implica que no quepan en su planteamiento, pero, sin duda, no juegan un papel determinante en la racionalización de la esperanza, rol que sí parecen ocupar en el caso, poco común, de Spinoza.

Respecto a (2), o sea, la oposición de la tradición literario-moral, es interesante señalar un lugar común de prevención contra las «imágenes mentales» de la esperanza. La razón estriba en que, lejos de apoyar o licenciar actividades en favor de lo esperado en la 
esperanza, pueden ejercer una oposición distractora e incluso favorecer un resultado contrario al esperado. Así lo indican Gabriel Segal y Mark Textor mediante el ejemplo de un piloto de carreras que, en el transcurso de una competición, invirtiera el esfuerzo y la energía mental descritos por Bovens no en la carrera, sino en la «imagen mental» de verse ganador de la carrera. En tal caso, la probabilidad de la victoria se vería seriamente comprometida si el piloto desviara su atención de cualquier otra cosa distinta de las rutinas y tareas propias de la conducción. En un caso así se pone de manifiesto que las «imágenes mentales» de la esperanza pueden ir en contra de lo esperado, hasta el punto de que sea aconsejable su neutralización, sin que por ello disminuya la esperanza del piloto en su victoria. A este respecto, es perfectamente plausible que el piloto haya dedicado horas de entrenamiento y formación para bloquear esas «imágenes mentales» de gloria o triunfo, en aras de evitar la ansiedad de la victoria y, en particular, imágenes obsesivas que puedan convocar el desastre.

La sabiduría práctica desaconseja desde antiguo la inversión de esfuerzo alguno en los «placeres de anticipación» propios de la esperanza, especialmente cuando estos vienen suscitados o alentados por ciertas fantasías que, en ocasiones, la acompañan. Piénsese, por ejemplo, en el cuento de Doña Truhana recogido por Don Juan Manuel en El conde Lucanor (1997 [1575], VII, Pp. 50-51). Como es habitual en sus narraciones, el noble solicita consejo de su criado Patronio, hombre sabio y de recursos, en torno a un asunto de negocios que, en las propias palabras del Conde, «tiene tantas ventajas que, si con la ayuda de Dios pudiera salir bien, me sería de gran utilidad y provecho, pues los beneficios se ligan unos con otros, de tal forma que al final serían muy grandes». Frente a ello, Patronio invoca las bondades de la prudencia, cuando dice que «el prudente se atiene a las realidades y desdeña las fantasías». La historia que le cuenta en esta ocasión versa sobre la figura de Doña Truhana, una mujer «más pobre que rica» que, yendo un día al mercado con una olla de miel sobre la cabeza, «empezó a pensar» en cómo la venta de su producto le permitiría comprar unos huevos; vender las gallinas - que, por supuesto, nacerían de los huevos-y comprar unas ovejas; vender unas ovejas - compradas con la venta de las gallinas-; «y así fue comprando y vendiendo, siempre con ganancias, hasta que se vio más rica que ninguna de sus vecinas» (1997 [1575], VII, p. 50). Llevada por esas «imágenes de anticipación» —nos dice, de hecho, que Doña Truhana «se vio»—, y porque había puesto «toda su confianza en fantasías», la olla se rompió en un descuido y «no pudo hacer nada de lo que esperaba y deseaba tanto» (1997 [1575], VII, p. 51).

Félix María de Samaniego, en otro célebre ejemplo, haciéndose eco no del cuento de Don Juan Manuel, sino de la fábula de La lechera y el cántaro de leche de La Fontaine, llama la atención sobre tres ideas en su propia versión del motivo: (1) la tendencia de la fantasía a confeccionar las imágenes más excelentes de lo esperado - lo que resitúa el asunto en una prevención de orden práctico frente al optimismo-; (2) la moderación de los afectos relacionados con esas imágenes, para evitar dejarse arrastrar por ellos; $y$, en última instancia, (3) la contención del apego, para que éste no se imponga a la propia estimación de la creencia, en la que ha de contemplarse el fracaso como una posible 
resolución, real, fácticamente probable e insidiosamente concreta. En sus propias palabras:

$$
\begin{aligned}
& \text { ¡Oh, loca fantasía, } \\
& \text { qué palacios fabricas en el viento! } \\
& \text { Modera tu alegría; } \\
& \text { no sea que, saltando de contento, } \\
& \text { al contemplar dichosa tu mudanza, } \\
& \text { quiebre su cantarillo la esperanza. } \\
& \text { No seas ambiciosa } \\
& \text { de mejor o más próspera fortuna; } \\
& \text { que vivirás ansiosa } \\
& \text { sin que pueda saciarte cosa alguna. }
\end{aligned}
$$

No anheles impaciente el bien futuro;

mira que ni el presente está seguro (Samaniego, 2005 [1781 y 1784], p. 53; II, 2, vv. 37-48).

Tampoco el ejemplo cinematográfico elegido por Bovens para apoyar su tesis parece responder con adecuación a sus intereses. Se trata de Cadena perpetua (The Shawshank Redemption, 1995), dirigida por Frank Darabont y adaptada por él mismo a partir de una novela corta de Stephen King de 1982, titulada Rita Hayworth y la redención de Shawshank (Rita Hayworth and Shawshank Redemption). La película se ha convertido en un lugar común de la discusión contemporánea sobre el concepto de esperanza y, en particular, sobre la búsqueda de ese «tercer factor» determinante para su definición.

La historia gira en torno a la estancia en prisión de Andy Dufresne (Tim Robbins), un banquero de Portland (Maine), culto y urbanita, condenado injustamente a dos cadenas perpetuas en la temible prisión de Shawshank, dirigida por el obtuso alcaide Samuel Norton (Bob Gunton) y sus secuaces. En términos generales, la trama está trazada en torno al modo de afrontar la vida en prisión por parte de los dos protagonistas: el propio Andy, un ardiente defensor del valor irrenunciable de la esperanza, y Ellis Boyd Redding alias Red (Morgan Freeman), un hombre duro formado en la cárcel, condenado también a cadena perpetua y que encarna ese tipo de desesperanza práctica, en cierto modo estoica, orientada a la supervivencia en entornos hostiles.

En uno de los momentos más reveladores del filme se aborda, precisamente, el papel que la esperanza juega entre los muros de Shawshank. Todo sucede tras un altercado anterior. Andy, una vez ganada la confianza del personal de administración — para quienes realiza trabajos de asesoría económica, la mayoría ilegales-consigue encerrarse en uno de los despachos de la oficina y colocar en el tocadiscos la canzonetta sull'aria de 
Las bodas de Figaro de Mozart, logrando con ello que suene la música a través de los altavoces del patio. Tras cumplir un largo período en aislamiento, sus amigos y compañeros más estrechos, entre los que se cuenta el propio Red, se sorprenden de que Andy no haya perdido la cabeza durante el cumplimiento de su pena:

ANDY. Tenía a Mr. Mozart haciéndome compañía (golpea y señala su cabeza). Estaba aquí. (Señala su pecho.) Y aquí. Ésa es la belleza de la música. Eso no te lo pueden quitar nunca. ¿No habéis sentido nunca la música así?

RED. Bueno, yo tocaba la armónica cuando era joven. Luego dejó de interesarme. No tenía mucho sentido aquí.

ANDY. No. Es aquí donde tiene todo el sentido. La necesitas para no olvidar.

RED. ¿Olvidar?

ANDY. Olvidar que hay cosas en el mundo que no están hechas de piedra. Que hay... hay algo dentro que no pueden coger; que no pueden tocar. Es tuyo.

RED. ¿De qué estás hablando?

ANDY. De esperanza.

RED. ¿Esperanza? Déjame decirte algo, amigo mío. La esperanza es una cosa peligrosa. La esperanza puede volver loco a un hombre. No sirve de nada aquí dentro. Sería mejor que te acostumbraras a esa idea.

En realidad, Red está previniendo al personaje de Andy de los peligros que encierra la esperanza a través de los «placeres de anticipación» que le son propios y, en especial, de sus fantasías, que pueden distraer de las rutinas necesarias para sobrevivir en un lugar inmundo como Shawshank. De lo que está hablando Andy, por su parte, es de la esperanza en sentido radical, de la actitud de mantenerse abierto a las circunstancias, de la necesidad de integrar las posibilidades del fracaso conjuntamente con las del éxito en un horizonte penumbroso, pero abierto.

La actitud de ambos personajes no puede ser más distinta, aunque no del todo contrapuesta: Red no se opone a Andy, aunque Andy acabe «tirando» de Red en no pocas ocasiones. Así como el primero se deja embargar por el poder liberador de la música, el segundo renuncia a ella, hasta tal punto que el día de su cumpleaños Andy obsequia a Red con una armónica, que éste se niega a tocar. Así como el segundo inicia todo tipo de proyectos que sirven para mejorar la vida en la prisión, no sólo la suya, sino la del resto de sus compañeros - ampliar los fondos de la biblioteca; fundar un repositorio de discos; ayudar a un joven recluso a superar el examen del graduado escolar...-, Red, sin criticar o despreciar ni una sola de sus aventuras, es incapaz de embarcarse por sí solo en todo aquello que arroje un mínimo de luz - y de sentidoa su rutina en la cárcel, reducida a la simple, cruda y mera resistencia cotidiana.

Por el contrario, Andy hace de su esperanza una virtud de entrega y dedicación que le permite mantenerse en vilo; prestar atención a lo que le rodea; evaluar y revaluar sus 
posibilidades de ser libre; integrar la incertidumbre; afrontar serenamente la posibilidad de la derrota $-y$, en general, la propia derrota-. Está claro que la sensación de bienestar asociada al cumplimiento de $p$-en este caso, «ser libre»— puede ser más intensa si viene animada o, si se prefiere, ilustrada por las fantasías de un resultado en el que uno «vea» que $p$ es satisfactorio, lo que quizá contribuiría a una mayor determinación para embarcarse en su búsqueda. Pero esto siempre es, en todo caso, algo opcional, contingente, creativo, pero no necesario para la esperanza: de hecho, ni en la novela original de Stephen King, ni en la propia película de Darabont da indicios Andy, de tener en su cabeza imagen alguna de su vida en libertad, sino que antes bien es la propia idea de «ser libre», en ese mágico y poderoso «espero ser libre», la que promueve, favorece $y$, hasta cierto punto, facilita todas sus actividades, sin renunciar a las dificultades e integrando, por lo tanto, la inevitable exposición al fracaso, a la ruina e, incluso, a la muerte.

El propio Santo Tomás — quien acepta, en lo básico, el modelo proposicional de la esperanza - fue el primero en señalar que las delectaciones que se dan en el mismo uso de la razón terminan colaborando con ella, como cuando uno razona sobre las probabilidades de éxito de un curso de acción y compromete su espera en ellas, «porque hacemos con más atención aquello en lo que nos deleitamos, y la atención ayuda a la operación» (quia illud attentius operamur in quo delectamur; attentio autem adiuvat operationem) (ST I-II, q. 33, a. 3, co.); consecuentemente, la proposición «Andy tiene la esperanza de ser libre», donde «ser libre» expresa un simple y llano contenido proposicional, genera tanta ilusión y entrega, sin precisar sus imágenes, que «implica de suyo ayudar a la operación, haciéndola más intensa» (per se habet quod adiuvet operationem, intendendo ipsam) (ST I-II, q. 40, a. 8, co.). De hecho, tras más de veinte años en prisión, el personaje interpretado por Robbins logra fugarse, revelando con ello un astuto plan, realmente difícil de llevar a cabo, en el que había estado trabajando, meditando y excavando aproximadamente desde sus primeros meses en prisión.

Nótese, por último, que ni el cuento de Doña Truhana, ni la fábula de La lechera, ni la historia de Andy Dufresne expresan las bondades estoicas de mantenerse a distancia de los bienes de la esperanza, como tampoco de sus placeres de anticipación. En realidad, frente al desenfado atolondrado del optimismo, que escamotea la posibilidad del fracaso de nuestros horizontes y cursos de acción, tanto Don Juan Manuel, como Samaniego, como King parecen alentar las razones de la esperanza con independencia de sus «imágenes». Tampoco niegan la posibilidad de que tales imágenes, en efecto, sean alimentadas.

De conformidad con las razones, argumentativas y hermenéuticas, que ponen de relieve el carácter problemático del modelo representacional de la esperanza, estamos ya en posición de arrojar una serie de conclusiones provisionales sobre la propuesta de Bovens. Adopto para ello el propio esquema platónico, en buena medida vigente, del que inferimos, en primer lugar, que el específico esperar de la esperanza provee de un «placer de anticipación» que, aun cuando se proyecte hacia el futuro, es tan radicalmente presente como anticipante de lo que está por venir. En otras palabras, la esperanza es —o, como mínimo, implica-un placer de presente, con base en una consideración 
mental en torno a un evento futuro, cuya sola posibilidad se concibe como deleitable: dicho de otro modo, «estar pre-complacido es estar complacido ahora mismo» (Vogt, 2017, p. 39).

La indeterminada expectación que consume a quien uno se mantiene a la espera de la mira de algo, a medio camino entre la incertidumbre más absoluta y la estimación probabilista, puede ser aligerada por esa inversión de energía mental que permite, al menos de manera momentánea o episódica, escapar de las circunstancias presentes en busca de alivio, consuelo, refugio o alegría. En este sentido, la sensación de bienestar puede ser más intensa si el contenido viene acompañado por imágenes mentales del resultado: al fin y al cabo, tales imágenes, que constituyen un cierto anticipo, nos permiten «vislumbrar una tierra [...] que puede ser alcanzada» (Godfrey, 1987, p. 27). Pero ateniéndonos al hecho de que no parece haber indicios de su necesidad para estar, de hecho, esperanzados, tales imágenes no pueden formar parte del conjunto de condiciones de la esperanza y gozan, por lo tanto, de una cierta autonomía: se trata de imágenes liberadas, cuya forja responde a una cierta normativa que les es propia.

La esperanza, en segundo lugar, provee, siempre según Platón, de un tipo de «prediscurso» (пробठокía) (Phlb. 32c) en relación al futuro, que, en línea con posiciones contemporáneas, posibilitaría una materialización concreta e imaginada de lo esperado y permitiría abordar con algo de serenidad los distintos escenarios, o sea, los estados proyectados del mundo futuro: la esperanza, por lo tanto, aporta una suerte de aproximación cartográfica de ese alboroto de lo posible que es el futuro $\mathrm{y}$, a su vez, adquiere forma de «resolución cognitiva», que permite una mejor subsistencia ante la precariedad de la incertidumbre (Pettit, 2004, p. 159). El contenido de ese «prediscurso» es, además, «agradable» (ท่ঠù) y, en tanto que proporciona una cierta seguridad para el esperanzado y logra promover, al mismo tiempo, una actitud proactiva, alerta y pendiente de lo que está por venir, la esperanza también es caracterizada como

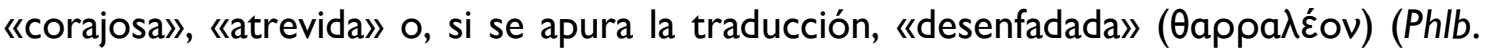
39c). El propio Aristóteles coincide con Platón en su consideración de la esperanza como algo fundamentalmente agradable que, al mismo tiempo, puede servir de apoyo al «coraje» (Өápoos); y, también como su maestro, consideraba el de Estagira que puede acompañarse la esperanza de una «representación mental de que está cerca lo que puede

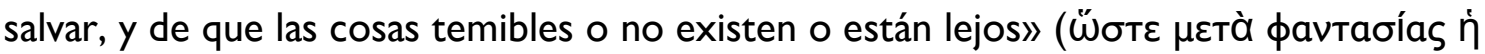

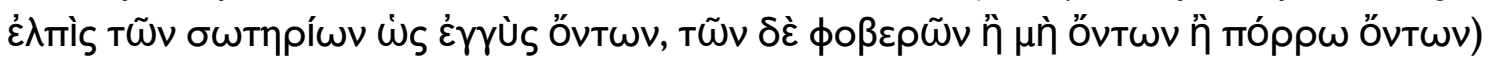
(Arist. Rhet. II, 5, 1383a17-19), sin que pueda reducirse condicionalmente a esa imagen; y sin que, de hecho, precise de ella.

Por último, y en tercer lugar, parece evidente que la forma del contenido de la esperanza la proporcionan los «discursos» ( $\lambda$ óyoı) interiores a los que Sócrates hacía referencia y que, siempre según la perspectiva platónica, resuenan en nosotros mismos. Las

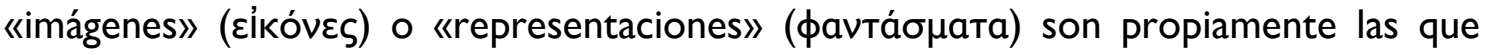
«están pintadas» ( $(\zeta \omega \gamma \rho a \phi \eta \mu \varepsilon ́ v a)$ en el libro de nuestras almas y permiten que «con

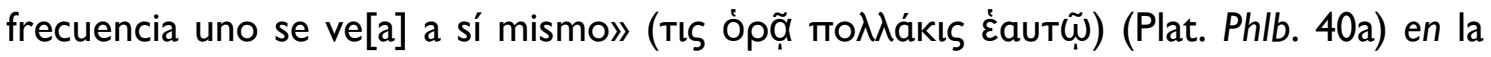
situación que se desea en la esperanza. Esta descripción estratigráfica, en la que no existe 
implicación de abajo arriba, pero sí de arriba abajo, formaliza el contenido material de la esperanza como un evento fundamentalmente proposicional, antes que como una «imagen», la cual, repetimos, o sobreviene, o es deliberadamente forjada. Con base en esta condición de las propias imágenes de la esperanza, tales fantasías no pueden ser condiciones necesarias de la esperanza, ni siquiera de manera «episódica», como sostiene el propio Bovens (1999, p. 675): todo parece indicar que las representaciones de lo esperado acontecen a veces de manera voluntaria, como cuando decidimos embarcarnos en la imagen, siempre agradable y estimulante, de que obtenemos lo que buscamos, de que estamos donde deseamos, de que nos acompaña quien amamos; a veces de forma súbita, como cuando esas mismas imágenes nos sobrevienen sin que podamos controlar su emergencia, aunque sí sus efectos sobre nosotros —ahí encuentra su justificación la insistente reserva de la tradición frente a las fantasías de la esperanza-

Expresado en clave analítica, la esperanza puede ser interpretada como un cierto tipo de evento mental, «con contenido proposicional» (Frede, 1985, p. 174). Su significado e implicaciones personales para el individuo serían los responsables de un tipo de placer relativo al futuro que, a su vez, se puede ver intensificado por las imágenes mentales del mismo, cuyo papel ni es necesario, ni tiene, por qué, ser necesariamente perjudicial. Se impone así la idea de que en la esperanza son distinguibles un contenido proposicional necesario, expresado por la proposición $p$ en «A espera que p»; y una imagen mental contingente de $p$. Dicho de otro modo, el concepto de esperanza dispone de un estatuto fundadamente proposicional y ocasionalmente representacional.

\section{| La liberación de las «imágenes de la esperanza» como base de legitimación para una «poética de la esperanza»|}

El trabajo de Bovens permite poner de manifiesto una cuestión determinante: de ser cierta la idea de que las «imágenes mentales» operan conforme a una legislación propia, que no viene dada por el «contenido proposicional» de la esperanza, sino antes bien por la propia creatividad de quien tiene esperanza, entonces es posible hablar de una poética de la esperanza. $\mathrm{Si}$, además, existe una neta distinción de orden práctico entre «imágenes» y «fantasías» de la esperanza, entonces no sólo es posible nutrir a la poética de orientaciones generales para la confección de imágenes expresivas de esperanza, sino que también será posible dotarla de normas específicas que salvaguarden los límites de su alcance, además de su sentido. En otras palabras, se encuentra aquí la base de justificación conforme a la cual desarrollamos, licenciamos, en los párrafos siguientes, una poética de la esperanza o, si se prefiere, de las imágenes de la esperanza, no sólo obedeciendo a razones estrictamente artísticas, sino también de orden práctico: la creación en torno a la esperanza puede informar a las personas de las probabilidades de éxito, pero también orientarlas hacia la transformación personal y social. Si existe un alivio en la esperanza, quizás en sus imágenes también haya consuelo, razones para 
perseverar, motivos para actuar. Quizá, después de todo, una imagen valga más que mil palabras.

La poética que proponemos, que aquí sólo puede ser esbozada, comienza por el trazado de un límite normativo —eludir el optimismo-, un objetivo creativo — cartografiar los escenarios de lo posible - y un horizonte de expectación — favorecer la resignación y la entrega al presente-.

i. Eludir el optimismo. Doña Truhana y la lechera comparten una misma tendencia no sólo a imaginar los resultados de la esperanza, sino a confeccionar la mejor versión de los mismos. Ellas representan, sin embargo, un límite normativo, de orden temático, que convendría evitar a toda costa en una poética de la esperanza: el artista no debe representar la certidumbre, sin base suficiente, de que lo esperado en el futuro se concretará de la mejor forma posible. En otras palabras, y por más contraintuitivo que resulte, el artista debe abstenerse del optimismo.

Conviene aclarar que no ponemos en duda los valores atribuidos al optimismo o sus bondades para la vida diaria (Peterson \& Chang, 2003). Antes bien, se acusa, en comparación con la esperanza, su grado de exposición a la falta de razonabilidad y sus dificultades para integrar la decepción. Esta debilidad constitutiva, contra la que históricamente previene la tradición moralista, la ha caracterizado recientemente Terry Eagleton en tres ideas fundamentales: (1) a diferencia de la esperanza, cuyo ejercicio tiene algo de virtuoso, por cuanto reconoce «la tozudez de la realidad» (Eagleton, 2015, p. 16) y «debe estar basada en razones», el optimismo ni puede ser considerado una virtud, ni entraña comportamientos evaluables libremente elegidos, al tratarse, más bien, de «una peculiaridad del temperamento» (2015, p. 18); seguidamente, (2) así como la esperanza tiende a un cálculo del presente en aras de una estimación futura de lo esperado, el optimista tiende a cerrarse ante el presente, a negar la gravedad de la situación y a considerar, en suma, que todo saldrá bien: «extiende un barniz monocromo sobre todo el mundo, sin percibir matices ni distinciones» (2015, p. 31); por último, (3) mientras que la esperanza se ancla en coyunturas concretas y contribuye a nuestra propia adaptación al entorno, el optimismo puede ser incluso «desadaptativo» (Eagleton, 2015, p. 16), refractario a la propia realidad cuando ésta contraviene nuestros propios intereses, querencias y deseos. En suma, al «perseverar demasiado con un argumento o una agenda de investigación, mucho más allá del punto en el que puede arrojar frutos» (Snow, 2013, p. 161), el optimista se sitúa en una perseverancia irracional y atolondrada, negacionista de la continua amenaza del fracaso y de nuestra pertinaz exposición a situaciones de vulnerabilidad.

Adam Kadlac, por su parte, considera que cualquier discusión en torno al optimismo o al pesimismo debería atenerse a las creencias sobre las que se construyen sus proposiciones. El optimismo no es, en todos los casos, fruto de la irreflexión o la ofuscación, sino que goza en ocasiones de creencias razonables. Dicho de otro modo, cuando existen evidencias suficientemente claras, ante una situación gravosa para el optimista, de que las probabilidades de superarla de la mejor manera posible son muy 
altas, entonces una mirada optimista sería lícita. Sin embargo, incluso en esos casos convendría recordar el subtexto moral del cuento de Doña Truhana o de la fábula de la lechera, pues «la evidencia», arguye Kadlac, «sobre qué ocurrirá en el futuro rara vez es suficiente para justificar creencias seguras sobre ese futuro», en especial en aquellos «asuntos altamente contingentes que tan dramáticamente afectan nuestras vidas diarias: enfermedad, empleo, relaciones, y cosas por el estilo» (Kadlac, 2015, p. 343).

Una poética de la esperanza, en suma, no puede reducirse, con independencia de sus bondades, a una normativa del «final feliz». Antes al contrario, en las imágenes de la esperanza han de quedar recogidas las posibilidades del éxito en pugna abierta con las del fracaso, concretadas en caminos y veredas que se abren, se cruzan y se cierran, sin expectativas de estabilidad, pero en la seguridad elemental y primordial $-y$ siempre bienvenida - de que la esperanza no implica imposibilidad; por el contrario, en los límites de una norma estética optimista, sólo se alimentaría la falsa certidumbre del éxito con exclusión no tanto de los obstáculos, como de la simple, radical y definitoria exposición al fracaso: entre las proposiciones «espero que p» $y$ «tengo la certeza de que $p$ será del mejor modo posible», dos mundos se oponen. Una imagen de esperanza es expresiva de una entrega radical al presente, con la luz del futuro; una imagen de optimismo se aproxima peligrosamente a la persuasión de la propaganda.

ii. Cartografiar los escenarios de lo posible. Las imágenes promovidas y creadas al amparo de una poética de la esperanza deberían contribuir no tanto a la intensificación de la creencia en lo esperado, como a la perseverancia de los agentes toda vez que el éxito sea posible. La fórmula, por lo tanto, se destila en los nada fáciles términos de una serena asunción de nuestros límites con arreglo a una coyuntura específica, marcada por la dificultad e iluminada, sin embargo, por un resquicio de resultados favorables que, pese a todo, se insinúa. En palabras del propio Bovens, «en tiempos de dificultad, hay un respiro bienvenido en la esperanza» (1999, p. 674). Pero este alivio no sólo es deleitable por sí mismo: frente a la precariedad informativa de la incertidumbre, las imágenes de la esperanza nos permiten abordar «el alboroto de la creencia» (2004, p. 159) y nos impelen, de alguna manera, a trazar una cartografía de oportunidades, errores, amenazas, fortalezas, y también de las debilidades de nuestra situación en relación al mundo y nuestra posición en él.

La poética de la esperanza, en su tarea de cartografiar los territorios de la esperanza, no puede, por su propio sentido, objeto y alcance, fijar con nitidez y detallismo los destinos; los objetos concernidos; los eventos que en su esperar se desean: debe limitarse, antes al contrario, a la misma indeterminación del resultado a la que apunta la esperanza y que comparte, en cierta medida, con los mapas de carreteras. En las imágenes de la esperanza, al igual que en la propia esperanza, no importa tanto el «qué» de lo esperado, como el «esperar» que se juega en el presente. De nuevo en palabras de Gabriel Marcel, «cuanto más tiende la esperanza a reducirse al hecho de aferrarse o hipnotizarse ante cierta imagen», tanto más podrá objetarse que es tan sólo ilusión, engaño de «tomar nuestros deseos por realidades»; antes bien, «cuanto más la esperanza trasciende la imaginación, de tal modo que me prohíbo imaginar lo que espero, tanto más esta misma objeción parece que se pueda efectivamente refutar» (Marcel, 1998 [1942], p. 56). 
Pensemos en Girl with balloon (original de 2002), la obra del célebre artista callejero Banksy. La forma es bien conocida: una niña estira el brazo con la mano abierta hacia un globo de color rojo, con forma de corazón, que huye en la dirección del viento, indicada sutilmente por el movimiento conjunto de la cuerda, el pelo y el vestido. No está claro si lo ha soltado o, por el contrario, el globo se le escapa. Tampoco sabemos hacia dónde va, pero sí que conocemos el mensaje que lo ampara: there is always hope, «siempre hay esperanza». Al igual que Banksy, los artistas acogidos a una poética de la esperanza no deberían posar su atención creativa en las tonalidades específicas del lugar al que destinan sus obras, sino que harían lo correcto en sugerir, desde la coyuntura y los espectadores a los que se dirigen, los perfiles abiertos del horizonte, las luces en lontananza, poniendo todo el peso creativo en señalar los caminos, los puntos de salida, los obstáculos, incertidumbres y, lógicamente también, las posibilidades. En otras palabras, una poética de la esperanza no puede, en modo alguno, determinar las imágenes de lo esperado, sino tan sólo apuntar los escenarios de lo posible, facilitar su apertura, reconocer la situación presente y reflejar el esperar de la esperanza en su constancia presente. Tan sólo cabe, en suma, señalar la dirección del viento.

iii. Favorecer la resignación y la entrega al presente. El horizonte de expectación para una poética de la esperanza, de las imágenes de la esperanza, se inicia con la palabra «resignación», en el sentido en que la utiliza Ariel Meirav en su propia teoría sobre el concepto. Habiendo detectado las insuficiencias explicativas del modelo dual, este autor piensa que la clave para discernir los motivos que llevan a Andy o a Red a dejarse llevar - no por la esperanza se halla en la actitud que ambos mantienen «hacia un factor externo relevante» (Meirav, 2009, p. 230). Interpretar ese «tercer factor» como algo positivo o favorable para aquello que esperamos entraña la posibilidad de que pueda actuar en nuestro beneficio y que, en caso contrario, existirá una razón suficiente para ello. Ahora bien, para que ese «factor externo» tenga sentido en el interior de su propia teoría, Meirav precisa de un repliegue argumentativo y de la modificación sustancial de uno de los dos elementos que integran el modelo dual: se trata, en suma, de reconceptualizar la condición desiderativa a través de la idea de la «resignación», que «designa aceptación o reconocimiento del hecho de que uno no tiene control o poder determinativo sobre algo» (Meirav, 2009, p. 228). Del «deseo» pasamos, ahora, al «deseo resignativo» que comparte algo de la mística «serenidad» (Gelassenheit) del Maestro Eckart.

«Resignarse», por lo tanto, no implica aquí una forma suave de desesperación, pues hace referencia, en todo caso, a la tranquila y alegre asunción de la falta de control sobre lo que está por venir, lo que no tiene por qué llevar aparejada la clausura para todo porvenir. Antes al contrario, en el «deseo resignativo», que a efectos prácticos es el «deseo sereno» de la esperanza, la luz está encendida, pero no controlamos el interruptor. $Y$ así está bien. Si la poética de la esperanza tiene un poder transformador para el espectador consistirá en poner de manifiesto esta falta genuina de control sobre las cosas, en cuya serena resignación y alegre aceptación se pone de relieve todo aquello 
que «hay de humilde, de tímido, de casto, en la esperanza auténtica» (Marcel, 2003 [1942], p. 47).

\section{|A modo de conclusión |}

La poética de la esperanza favorece, a través de sus imágenes, el desasimiento que es propio del esperar de la esperanza y que permite, en buena medida, una expresa ocupación en la vida cotidiana. Ejemplo de esta cláusula, con la que concluyo este estudio, lo encontramos en un cuadro de Gustav Klimt, originalmente titulado Visión y rebautizado, por compartir temática y modelo con otro anterior, Esperanza II (Die Hoffnung II) (1907-1908). La imagen recoge la figura estilizada de una esbelta joven, en avanzado estado de gestación. Salvo los pechos desnudos, emblema genuino de la amable nutrición, el resto de su cuerpo lo cubre un largo vestido decorado con formas geométricas, en algunos tramos ciertamente intrincadas. Con los ojos cerrados, inclina la cabeza hacia el vientre; la mano derecha levantada en actitud de atención; el brazo y la mano izquierdos, sugeridos a través del paño, se posan sobre la barriga, bajo cuya piel percibe la mamá el movimiento del bebé. Se suele indicar que la madre tiene aquí un gesto de resignación, en un sentido cercano a la desesperanza. Sin embargo, bajo la integración de los temores diarios; bajo el gesto cansado; bajo la continua amenaza de la muerte -en la tétrica forma de una calavera que se asoma tras la tripa-; bajo el paño brocado de oro, la madre responde, repetimos, posando su mano sobre el vientre, con un amor incombustible, radicalmente presente, imbuido de ternura y determinación para mantenerse a la luz de la esperanza.

El artista logra en este cuadro eludir la tentación del optimismo al integrar, en una sola imagen, el temor, el cansancio y la muerte, pero también el amor y los cuidados de la madre ante el inminente nacimiento, indicativos de un presente continuo que se proyecta hacia el futuro; también cartografia la tensión del éxito y del fracaso en la siempre larga espera del embarazo, sin determinar con nitidez las imágenes concretas de su éxito, pero dejando abiertas todas las posibilidades, también, por qué no, las favorables; y por último recoge, en el sutilísimo lenguaje corporal de la madre, uno de los más exactos y hermosos retratos de la maternidad: el deseo resignado de que todo salga bien, bajo el conocimiento de que sólo algunas cosas dependen de ella. Pero también en una entrega absoluta y serena al presente, también en la consciencia de que éste sí depende por completo de ella.

\section{| Referencias |}

Beyleveld, Deryck (2012). Hope and Belief. En R.J. Jenkins y W.E. Sullivan (eds.). Philosophy of Mind (pp. 1-36). New York: Nova Science Publishers.

Blöser, Claudia (2019). Hope as an Irreducible Concept. Ratio 32 (3), 205-214. https://doi.org/10.1111/rati.12236 
Bovens, Luc (1999). The Value of Hope. Philosophy and Phenomenological Research 59 (3), 667-681. https://doi.org/10.2307/2653787

Day, John Patrick (1969). Hope. American Philosophical Quarterly 6 (2), 89-102. https://www.jstor.org/stable/20009295

Diès, Auguste (ed.) (1941). Oeuvres completès. Tome IV, 2e Partie: Philèbe. Paris: Les Belles Lettres.

Downie, Robert S. (1963). Hope. Philosophy and Phenomenological Research 24 (2), 248251. https://doi.org/10.2307/2104466

Frede, Dorothea (1985). Rumpelstiltskin's Pleasures: True and False Pleasures in Plato's Philebus. Phronesis 30 (2), 151-180.

Godfrey, Joseph J. (1987). A Philosophy of Human Hope. Dordrecht: Martinus Nljhoff Publishers.

Gravlee, G. Scott (2020). Hope in Ancient Greek Philosophy. En Steven C. van den Heuvel (ed.). Historical and Multidisciplinary Perspectives on Hope (3-23). Cham: Springer.

Kadlac, Adam (2015). The Virtue of Hope. Ethical Theory and Moral Practice 18 (2), 337-354. https://doi.org/10.1007/s10677-014-9521-0

Kwong, Jack M.C. (2019). What is Hope? European Journal of Philosphy 27 (1), 243-254. https://doi.org/10.1111/ejop.12391

Lomba, Pedro (ed.). (2020). Baruj Spinoza. Ética demostrada según el orden geométrico. Madrid: Trotta.

Marcel, Gabriel (2005). Homo viator. Salamanca: Sígueme.

Marcel, Gabriel (2003). Ser y tener. Madrid: Caparrós.

Martin, Adrienne M. (2014) How we hope: a moral psychology. Princeton: Princeton University Press.

Meirav, Ariel (2009). The Nature of Hope. Ratio 22 (2), 216-233. https://doi.org/10.1111/j.1467-9329.2009.00427.x

Milona, Michael (2020a). Discovering the Virtue of Hope. European Journal of Philosophy J Philos 28, 740- 754. https://doi.org/10.1111/ejop.12518

Milona, Michael (2020b). Philosophy of Hope. En Steven C. van den Heuvel (ed.). Historical and Multidisciplinary Perspectives on Hope (99-116). Cham: Springer.

Milona, Michael and Stockdale, Katie (2018). A Perceptual Theory of Hope. Ergo: An Open Access Journal of Philosophy 5 (8), 203-222. https://doi.org/10.3998/ergo.12405314.0005.008

Moellendorf, Darrel (2006). Hope as a Political Virtue. Philosophical Papers 35 (3), 413433. https://doi.org/10.1080/05568640609485189 
Orden de Predicadores (1955-1956). S. Thomas Aquinatis. Summa Theologiae (5 vols.). Madrid: BAC.

Peterson, Christopher \& Chang, Edward C. (2003). Optimism and Flourishing. En Keyes, Corey L.M. \& Haidt, Jonathan (eds.). Flourishing: Positive psychology and the life well-lived (55-79). Washington, DC, US: American Psychological Association.

Pettit, Philip (2004). Hope and its Place in Mind. The Annals of the American Academy of Political and Social Science 592, 152-165. https://www.jstor.org/stable/4127684

Pradier, Adrián (2020). Integrar la incertidumbre. Un estudio sobre la esperanza. Ethika+ 2, 167-185. https://doi.org/10.5354/2452-6037.2020.58860

Rodis-Levis, Geneviève (ed.) (1970). René Descartes. Les passions de l'âme. Paris: Vrin.

Segal, Gabriel \& Textor, Mark (2015). Hope as a Primitive Mental State. Ratio 28 (2), 207-222. https://doi.org/10.1111/rati.12088

Shapiro, lan (ed.). (2010). Thomas Hobbes. Leviathan or the Matter, Forme, \& Power of a Common-Wealth Ecclesiasticall and Civill. London: Yale University Press.

Snow, Nancy E. (2013). Hope as an Intellectual Virtue. En Michael W. Austin (ed.). Virtues in Action. New Essays in Applied Virtue Ethics (153-170). Basingstoke: Palgrave Macmillan. https://doi.org/10.1057/9781137280299_11

Tovar, Antonio (ed.) (1999). Aristóteles. Retórica. Madrid: Centro de Estudios Políticos y Constitucionales.

Vogt, Katja (2017). Imagining Good Future States: Hope and Truth in Plato's Philebus. En Richard Seaford, John Wilkins y Matthew E. Wright (eds.). Selfhood and the Soul: Essays on Ancient Thought and Literature in honour of Christopher Gill (33-48). Oxford: Oxford University Press.

Wheatley, James Melville Owen (1958). Wishing and Hoping. Analysis 18 (6), 121-131. https://doi.org/10.1093/analys/18.6.121

\section{| Nota biográfica |}

Adrián Pradier (Zaragoza, 1979). Doctor en Filosofía por la Universidad de Salamanca, especializado en Estética y Teoría de las Artes. Entre 2006 y 2020 fue profesor adjunto de la Escuela Superior de Arte Dramático de Castilla y León, donde impartió clases de Estética, Pensamiento Filosófico y Teoría e Historia de las Artes del Espectáculo. Entre 2015 y 2020 ejerció labores docentes en la Universidad Internacional de La Rioja. Entre 2016 y 2020 fue profesor asociado al Departamento de Filosofía de Estética de la Universidad de Valladolid y, desde 2020, es Profesor Ayudante Doctor del mismo, en asignaturas de Estética y Teoría de las Artes. Docente en distintos másteres universitarios, es también miembro del GIR "Ciencia y Arte en Filosofía" de la UVa, del 
GIR "Estética y Arte Contemporáneo" de la Universidad de Navarra y del Grupo de Investigación en Artes Escénicas (ARES) de UNIR. 